\title{
Study of the undergraduate student's innovation and entrepreneurship training strategy
}

Guorong Sui, Binming Liang, Hongzhi Jia

Guorong Sui, Binming Liang, Hongzhi Jia, "Study of the undergraduate student's innovation and entrepreneurship training strategy," Proc. SPIE 10452, 14th Conference on Education and Training in Optics and Photonics: ETOP 2017, 104524Q (16 August 2017); doi: 10.1117/12.2269100

SDIE Event: 14th Conference on Education and Training in Optics and Photonics, ETOP 2017, 2017, Hangzhou, China 


\title{
Study of the undergraduate student's innovation and entrepreneurship training strategy
}

\author{
Guorong Sui, Binming Liang, Hongzhi Jia \\ University of Shanghai for Science and Technology, No. 516 JunGong Road, Shanghai 200093, China
}

\begin{abstract}
With the development of science and technology, all teachers in the college will face how to stimulate the undergraduate student's ability and make them to be an excellent engineer. For solving these questions, a new scheme with three steps has been designed. First, students will participate in the class teaching activity not only teacher. It will encourage them to read many extracurricular books and articles. Second, they will be required to think and design more new experiments after complete all experiment about the textbook and join more competition of the innovation and entrepreneurship. Third, some students who have more time and ability can early enter into his advisor professor's lab to join various science and technology project. By this scheme, it will be realized to improve student's innovation ability and be a brilliant engineer.
\end{abstract}

Key words: stimulating innovation ability of the students; excellent engineer; class teaching; more experiment and competition; academic advisor scheme;

\section{Introduction}

Comrade Xi Jin-ping put forward that nation will be prospered and stronger by following with the prospering and stronger of science and technology in the national science and technology innovation conference [1]. He also said that implementing the innovation -driven development strategy is inevitable choice to face the development environmental change, grasp the development autonomy and improve the core competitiveness. And is inevitable choice to quickly change the economic development mode and break the economic development deep-seated problem. It is also the inevitable choice to guide country economic development new habitus and keep country economic continue and healthy development. In the 21 century, innovation ability is a main expression of the national competitiveness. The competition between the countries has changed the competition of innovation talents. Following aging of population and consumption of natural resources, the driving force of labour force and material cost to economic increasing is being 
weakened. So, science and technology innovation become the core driving force of national sustainable development. It has been the important issue to build the national system innovation mechanism to improve the innovation of science and technology in recent years. Act as the important base and fountain of innovation, university is the cradle which cultivates the innovative talents of science and technology. The undergraduate is mainly cultivated to serve the technology innovation of enterprise. And the postgraduate is mainly cultivated to increase the innovation ability of science and technology. Most university doesn't get the expectant cultivated effect of talents over the years because of our education system and mode. Then, how to promote the appropriate reform of undergraduate's education and build innovation incentive strategy have important meaning [2, 3]. Our Optoelectronic information science and Engineering undergraduate majors in the discipline construction and laboratory construction are among the best in the school and even the whole country. We proposed some new method to receive good effect of innovation ability training on the base of several years teaching and scientific research work and combining actual scientific research project with student's innovation ability training. Leading an undergraduates teaching research team successfully applies to various innovative projects. We build the academic advisor scheme to attract all of the students to early join the scientific research term of the teachers. By the training, they can obtain more progress. The students participated in the various competitions of national and Shanghai and won the prize. The practice results show that the incentive strategy and cultivation mode have a certain scientific.

\section{Feature of innovation training}

Undergraduate education always is the base of national quality-oriented education and talent education. For solving innovation ability training in undergraduate education, we firstly need to study the status quo and characteristics of undergraduate education, and find a suitable solution according to the characteristics of the status quo. Finally, we may obtain good results and effect toward the students' innovative strategies.

\subsection{Influence of lesson and teaching method}

Now, the teaching of university is still cramming system as the main method. And it needs the student's self-study as supplement method. However, these teaching modes only inherit the teaching form of the middle school so that the students are still in a state of passive learning. The goal is still 
"teaching to the test". Concentrating on the class, doing various exercises training, questioning toward the teacher, preparing lessons before class and review can help the students to get the outstanding test score. However, they don't bring doubts and get their own ideological understanding. The students can't understand really the true meaning of the innovation and realize the innovation.

On the other hand, some universities ask for and train the students to dare to doubt the academic authority. It is a good idea. But doubt can't be too simple and one-sided. Because the base of doubting the academic authority is that the students has mastered the content and essence of the theory which is suggested by the academic authority. The students need absorb and understand deeply the essence and the core idea of the academic authority's theory. In the base of these thought, they can begin to doubt some insufficient preciseness even mistakes of the academic authority's theory, not to simple and blindly doubt. For getting this effect, an appropriate teaching method is important to improve the self-confidence and stimulate the innovation ability of the students.

\subsection{Influence of the internship and practical training}

In the current undergraduate education reformation, both basic courses and specialized courses are equipped with a certain amount of experiment teaching. This has fully showed the achievements which stick to the education reform. It is well known that the internship and practical training is very important to the higher education. It not only affects the effect of undergraduate teaching quality, but also influences the cultivation of students' practice ability and innovation ability. To improve student's quality, analysis of the method has the important significance to solve the problem. However, the establishment of the experiment link does not mean that the success of the experiment teaching, more does not mean the improvement of undergraduate teaching quality. On the contrary, inappropriate experiment teaching link will seriously affect the students' practical ability and innovation ability, and further affect the students' understanding of theory. In order to solve this problem, many schools visit some famous abroad universities to reform the experiment teaching. By adopting the basic experiment to combine with the extend experimental teaching mode, using the expansion of the laboratory resources can give students free play experiment project on the base of finishing step-by-step the basic experiment. At the same time, we build the academic advisor scheme. We distribute one academic advisor for every student. The teacher will take them to visit his laboratory and tell them what he do the project. We hope that it can attract the students to early join the scientific research term of the teachers. The students can propose own viewpoint to the project, 
even ask the teacher for providing some devices to verify their idea. By the training, they can obtain more progress and self-confidence. This is a kind of progress, but the progress of the teaching pattern itself is not enough. In addition, how to undertake to the student in the undergraduate course teaching to further the theory guidance and scientific research practice after class is of great importance to inspire and motivate the students' innovation ability.

\section{Innovation incentive strategy of undergraduate education}

Aim at the characteristics of undergraduate education, we proposed some effective methods through the analytical investigation and teaching and research practice. In the actual process of training, these methods also have obtained the certain effect. These methods are showed following several aspects.

\subsection{Improvement of undergraduate teaching method}

In order to improve the negative effects of past teaching system and reform measures, the students' enthusiasm and confidence, and further motivate students to innovate, we do the reformation beginning from the classroom teaching. The teachers have a class and students listen to ask questions are key in the previous classroom teaching. In order to change this kind of low efficiency and blindness, we need combine the teachers' classroom instruction, the teaching themselves and the initiative discussion of the students is combined. Finally, the total score not only depend on the class exercise and test score but also depend on the initiative discussion of the students and experiment score. At the beginning of the course, the teacher needs to complete the particular teaching plan, and distribute earnestly the whole class time. Separating some flexible class time from the whole class time is used to realize that the students teach themselves and do the discussion each other. The main body of teaching and order is controlled by the teacher. The teacher can draw up a task plan, and ask the student to make in advance the lesson report after the class.

Ready to report to the students and the information after the finish on the day of the lecture in the basic content of cases, set aside a part of the time by the students to the platform for teaching, after class, to explain in detail the various kinds of information and prepare reports. Requirements report content related to the lectures as far as possible, and finish the related content of teaching and report, put forward their own opinions and views, and interact with other students, ask each other to solve. The teachers to maintain classroom order is given priority to, and guide students in correct 
order. Such not only can improve the understanding of students to teacher lectures, and also puts forward higher requirements on after-school self-study. And students own teaching on the one hand, can better realize the teaching emphasis and difficulty of the theory, at the same time also can let them understand the theory constantly find themselves, they have been found more conducive to problem, ask questions, analyze and solve problems. Discussion between students can enrich the classroom atmosphere, relatively simple than ever hypnotic trance when teachers, classroom atmosphere active obviously, students are willing to actively participate in the discussion, ask each other, each other to solve. Can enhance each student's participation, thus to improve the understanding of the theory, through the debate with this way of discussion of the training is a good way to inspire students innovative thinking, improve the quality and ability of students. The teacher will be continued to finish the class teaching according to the teaching plan. When the students prepared their reports and information, the teacher will separate a part of class time to the student who can have a lesson to the other students on the class rostrum. He will lecture all kinds of information and preparative report after the class. The report content is required to have a relation with the lesson content. And the student must propose his own viewpoint and perspective after finishing the class and report. And then he needs to interact with the other students, and answer their questions each other. The teacher only maintains the class order and guides the students to discuss in correct order. So, the students not only can improve the understanding of the lesson content, but also puts forward higher requirement on after-school self-study. The students teach themselves can help them to understand the difficulty and emphasis of the theory teaching and improve their thought. It is beneficial that they explore, raise and solve some questions. Discussion between the students can simulate and enrich the classroom atmosphere. Almost all of the students would like to participate in the discussion and contribute their wisdom and thoughts. After the discussion and the training, the quality and ability of the students can be improved to simulate the innovation.

\subsection{Cultivation of the practice teaching}

The practice teaching is reformed. Firstly, the traditional course experiment is reformed. Each student will be needed to complete a particular prepared report before beginning the experiment. The purpose, equipment, method and prospective result data table of the experiment must be beforehand thought and made. When these above works are checked and accepted by the teacher, the students can enter the lab to do the experiment. The final experiment score will be decided by the whole 
experiment processing rather than experiment result, phenomenon and report. Some students which find or submit new question and want to do the further experiment will be given support and encourage. If they can solve the question, they will get more harvest than the other even submit a high level paper or get the social recognition. The sense of achievement will make the students to be more excellent and interest in the science theory and technology practice. Through the reform, the innovation and creation thought of the student will be encouraged greatly. In fact, more and more students are encouraged to enjoy the various national or province science and technology competition. Some of them get the good grades and enter better school for further study. On the other hand, the students learn and cultivate solidify and cooperation, rational division of labor and logical thinking ability. Though these practices, the students studied much knowledge outside textbooks and cultivate their innovation ability. All these training will lay a solid foundation for students to enter the society in the future. The reform of electronic information specialty can be driven. And it will promote to generate innovative talents of electronic information specialty [4]. In addition, some outstanding students will get the priority of exemption postgraduate qualification and scholarship. If the condition is appropriate, the students can be taken in scientific research project following the teacher. These students will participate in various scientific research activities and do the work reports in the term. At the same time, some outstanding students will obtain research allowance. These means can inspire greatly undergraduate's learning initiative and scientific research enthusiasm. And the undergraduates repeatedly act as the important role in the scientific research work. In the innovation of scientific research, find an innovative question may be more important than to get an innovation solution to problem. The undergraduate not be restricted by the traditional theories and thinking, and dare to query and innovate. So, this kind of undergraduate often proposes some novel and interesting question.

\section{3 train sharp outsight of the student}

The innovation comes from the intensive observation and analysis to the thing. So, we need to strengthen the observation and analysis ability of the students to the things and phenomenon. In the process of experiments and research, the students don't ignore some phenomena and problems but carefully studied every detail because every innovation may come from the "unusual" discovery, analysis and research. So you need to cultivate students to find some "differences" in the ordinary, and analyze and study inner meaning of these "differences" combining with theoretical analysis. The 
innovation ability and potential of students will be improved and stimulated by constantly finding one by one novel question [5]. We should correctly guide and inspire students to let them jump out from the simply learning to book and mathematic operation. At the same time, we should notice to protect the enthusiasm of the students in the processing of cultivation and stimulation. At the start of research, we should understand that they may generate some erroneous judgement because of their very high warmth and lacking theoretical basis. In the process, teachers need to help and guide the students to find the question by themselves rather than simply point out their mistakes even laugh at them. At last, the students can realize their mistakes and understand that the innovation is not simple and easy thing. They also understand that they still need many hard works and undergo the countless times failure even if they find a novel question and a good solution method. The students also raise their toughness, faith and confidence when they train and exercise their own observation and analysis force.

\section{Summary}

In conclusion, the teachers need patience, perseverance and confidence to cultivate and stimulate the student's innovation ability. And they need cooperated with appropriate teaching method and incentive strategy. The cultivation of the innovation ability is not a short-term rather needs a long-term training. The teacher should be strict with the students and corrected their bad habit and method. On the other hand, we also guide patiently the students and really care for their thinking and idea. Every student is an independent individuality person, and not be treated by the machine-made means. We teach students in accordance of their aptitude according to their different characteristic. Through the exchanges and assistance and supervise each other between the students, we can create a harmonious, mutual improvement environment. It is a good basis to improve the students to realize science and technology innovation. These works will provide a lot of different innovative talents for different company. 
Acknowledgement: This work was partly supported by National Basic Research Program of China (973 Program(Grant No. 2015CB352001, 2016 Key teaching reform project of SHMEC: The construction of practical teaching system for the cultivation of Engineering Innovative Talents, and series of excellent undergraduate research projects of USST.

\section{References}

[1] Xi Jin-Ping. Strive for the construction of world science and technology [J]. Practice (thoughts and theory), 2016(7):19-20.

[2] Zhu Ping. Exploration of innovation incentive mechanism of the undergraduate [J]. Examination Weekly, 2011(92):205-207.

[3] He Yong-Ping. Learning freedom of undergraduate and cultivation of innovation talent [J]. Southwest University of science and technology (Higher Education), 2012; 102(1):49-54.

[4] Yu Miao, Wang Ru. Promotion of undergraduate electronic design contest to the cultivation of electronic information innovation talent $[\mathrm{J}]$. China Education Innovation Heral, 2012(10):189-189.

[5] Cai Ya-Min. Several questions in the undergraduate innovation ability training processing [J]. Modern Education Management, 2003(2):45-46. 